\title{
Extended Spectrum Beta Lactamase (ESBL) Producing Neisseria meningitidis - Isolated from a Case of Pneumonia
}

\author{
O. Sasikumari, Angel Mary George, and K. L. Sarada Devi
}

\section{ABSTRACT}

\begin{abstract}
Neisseria meningitidis (meningococci) is the most common cause of bacterial meningitis in all age groups. Invasive meningococcal disease manifesting as meningococcal pneumonia is a very rare clinical condition. Here we have a 72 year old male who presented with meningococcal pneumonia and sepsis following a flu like illness. It is notable that he did not develop the syndrome of meningococcemia or its associated complications. This patient was treated with injections of Piperacillin-Tazobactum and Azithromycin because of the unusual antibiotic resistance pattern of the organism. He recovered completely without any sequelae. The meningococci isolated was an ESBL (extended spectrum beta lactamase) producing strain, hence it was resistant to Penicillin and third generation Cephalosporins which are usually used for the treatment of meningococcal infections. This strain was also resistant to Ciprofloxacin .This poses a threat to the community as well, especially because Ciprofloxacin is used as a chemo prophylactic drug by the contacts of the patient and the laboratory workers dealing with the patient's clinical samples.
\end{abstract}

Keywords: Meningococci; meningitis; ESBL; Ciprofloxacin; Azithromycin; pneumonia.

\section{INTRODUCTION}

Neisseria meningitidis (meningococci) is the most common cause of bacterial meningitis in all age groups. Meningococcal pneumonia is a rare clinical condition, but it is the most common non neurological organ disease caused by this pathogen.

Meningococcal pneumonia usually affects the elderly (> 65 years). More than $90 \%$ isolates of Neisseria meningitidis are susceptible to Penicillin. In resistant cases third generation Cephalosporins are used, but here we have a case where the organism was resistant to Penicillin, third generation Cephalosporins and Ciprofloxacin.

\section{CASE REPORT}

A 72 year old male patient presented with history of fever, dry cough and rhinorrhea of four days duration following which he developed purulent expectoration and severe dyspnoea. He was a known case of COPD (chronic obstructive pulmonary disease). A provisional diagnosis of COPD with acute infective exacerbation was made and he was admitted in the Government Medical College, Thiruvananthapuram which is a tertiary care centre in Kerala, South India. His blood pressure was $90 / 60 \mathrm{mmHg}$ and the
Submitted : June 01, 2021

Published : June 30, 2021

ISSN: 2593-8339

DOI: $10.24018 /$ ejmed.2021.3.3.908

\section{Dr. O. Sasikumari*}

Associate Professor, Department of Microbiology, Government Medical College, Thiruvananthapuram, Kerala, India.

(e-mail: sasikumarimohan @ gmail.com) Dr. Angel Mary George

Senior Resident, Department of Microbiology, Government Medical College, Thiruvananthapuram, Kerala, India.

Dr. K. L. Sarada Devi

Professor and Head of the department, Department of Microbiology, Government Medical College, Thiruvananthapuram, Kerala, India.

*Corresponding Author pulse rate was 96/minute. He was nebulized with Levosalbutamol and Ipratropium. Injections of Methyl prednisolone were given as supportive measures to combat shock. The patient was immediately started on intravenous Ceftriaxone, Azithromycin and Linezolid. The patient's hematological investigations were done along with chest $\mathrm{X}$ ray. His sputum sample and blood samples were also sent for Microbiological investigations.

Chest X-ray showed right lower zone consolidation and right middle zone pneumonitis (Fig. 1).

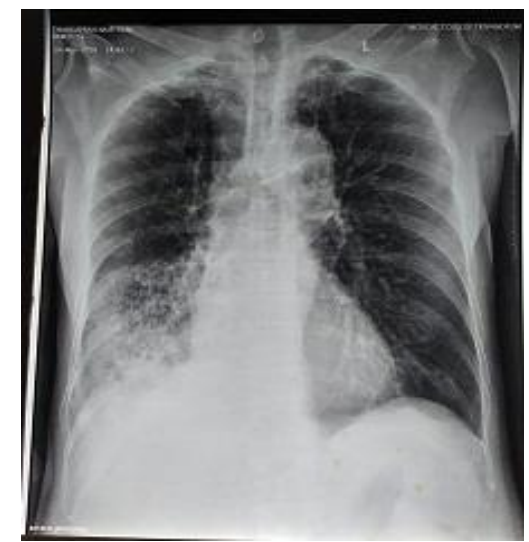

Fig. 1. Chest X-ray of the patient. 
The hematological values showed polymorphonuclear leucocytosis.There was no thrombocytopenia. Other parameters like renal function, liver function, electrolytes etc. were within normal limits. Later Oseltamivir phosphate tablet was also started for the patient.

\section{A. Microbiological Investigations of the Sputum Sample}

Macroscopic appearance - Sputum was purulent.

\section{B. Gram Stain of the Sputum}

There were plenty of pus cells. Normal flora was absent. There were plenty of gram-negative cocci in pairs seen both intracellular and extracellular (Fig. 2).

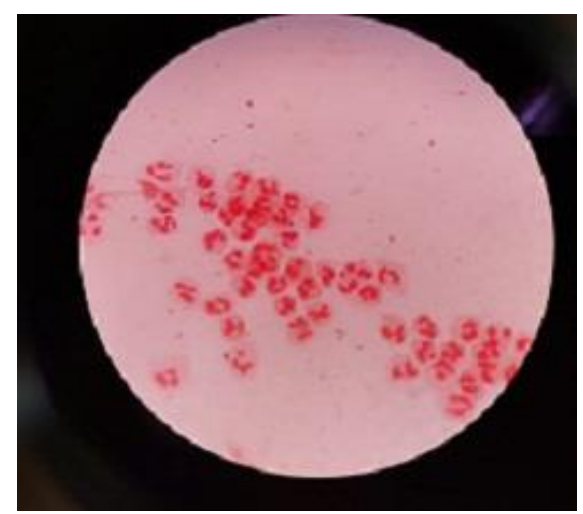

Fig. 2. Gram stain of sputum showing intracellular and extracellular gramnegative cocci in pairs.

Ziehl Neelsen staining of the sputum did not show the presence of acid-fast bacilli. The sputum was cultured on Blood agar, Chocolate agar and MacConkey agar.

\section{After 24 hours of Incubation}

Blood agar and Chocolate agar showed predominant growth of grey moist minute colonies of 0.5 to $1 \mathrm{~mm}$ size. There was no hemolysis on blood agar. Normal flora was absent. There was no growth on MacConkey agar.

Gram stain of the growth showed Gram negative diplococci.

The following biochemical reactions were done to identify the isolate:

- Catalase - positive;

- Oxidase -positive;

- Nitrate -not reduced to nitrite;

- Fermentation of glucose- fermented;

- Fermentation of maltose-fermented;

- No growth at $22{ }^{\circ} \mathrm{C}$.

The common gram-negative cocci of clinical isolates from which Neisseria spp has to be differentiated areAcinetobacter spp and Moraxella spp. Some features which can help in a preliminary identification of the organism are given in Table I.

Based on the morphology, cultural characteristics andbiochemical reactions, the isolate was provisionally identified as Neisseria meningitidis

Microbiological investigations of the blood samples (two samples) of the patient also yielded pure growth of Neisseria meningitidis. Since the study centre was a resource limited setting, the isolate was sent to the public health laboratory of Thiruvananthapuram. They identified the isolates as Neisseria meningitides by Vitek-2 and PCR. Despite these findings the patient did not show any features of meningitis or the syndrome of meningococcemia

TABLE I: IDENTIFICATION OF GRAM-NEGATIVE COCCI

\begin{tabular}{|c|c|c|c|}
\hline $\begin{array}{l}\text { Biochemical } \\
\text { reaction/other } \\
\text { features of } \\
\text { identification }\end{array}$ & $\begin{array}{l}\text { Neisseria } \\
\quad \text { spp }\end{array}$ & $\begin{array}{c}\text { Acinetobacter } \\
\text { spp }\end{array}$ & $\begin{array}{l}\text { Moraxella } \\
\quad \text { spp }\end{array}$ \\
\hline $\begin{array}{l}\text { Morphology and } \\
\text { arrangement }\end{array}$ & $\begin{array}{l}\text { Diplococci } \\
\text { seen both } \\
\text { inside and } \\
\text { outside the } \\
\text { pus cells }\end{array}$ & $\begin{array}{l}\text { Cocco bacilli } \\
\text { Scattered or } \\
\text { arranged in } \\
\text { groups, Not seen } \\
\text { inside pus cells }\end{array}$ & $\begin{array}{l}\text { Diplococci } \\
\text { or seen in } \\
\text { groups. Not } \\
\text { seen inside } \\
\text { pus cells }\end{array}$ \\
\hline Growth at $22{ }^{\circ} \mathrm{C}$ & Absent & Present & Present \\
\hline $\begin{array}{c}\text { Growth on } \\
\text { MacConkey agar }\end{array}$ & Absent & Present & Present \\
\hline Catalase & Positive & Positive & Positive \\
\hline Oxidase & Positive & Negative & Positive \\
\hline Nitrate & Not reduced & Not reduced & $\begin{array}{l}\text { Reduced to } \\
\text { nitrite }\end{array}$ \\
\hline $\begin{array}{c}\text { Fermentation of } \\
\text { glucose }\end{array}$ & + & $+/-$ & - \\
\hline $\begin{array}{c}\text { Fermentation of } \\
\text { Maltose }\end{array}$ & + & - & - \\
\hline DNAase & - & - & + \\
\hline
\end{tabular}

The antibiotic sensitivity tests were done as per CLSI (Clinical and Laboratory Standards Institute) guidelines. The isolates from the sputum and blood samples showed the same antibiotic sensitivity pattern. They were sensitive to Azithromycin, Rifampicin, Gentamicin, Meropenem, Chloramphenicol and Piperacillin-Tazobactum. The organism was resistant to Penicillin (MIC 0.7) and third generation Cephalosporins-Cefotaxim and Ceftriaxone (MIC 0.2 ) showing that it was an ESBL producing strain ESBL production by meningococci is a very rare phenomenon. The organism was also resistant to Ciprofloxacin (MIC 0.2). Etest was done in the treating centre. MIC was confirmed with Vitek 2 antibiotic sensitivity card.

The treating centre is one of the nodal centres for AMR (antimicrobial resistance) surveillance of the country, so this unusual antibiotic resistance pattern was immediately informed to NCDC (National centre for disease control), New Delhi. The isolate was sent to NCDC, and they also confirmed the resistance pattern using molecular methods

\section{Treatment}

The patient was treated empirically with Injections of Ceftriaxone, Azithromycin and Linezolid. After getting the antibiotic susceptibility test reports, Ceftriaxone was stopped, and the clinicians started injection Piperacillin-Tazobactum. Oseltamivir phosphate tablet was also given from the second day of admission. The parentral treatment was given for seven days after which the patient recovered completely without any sequelae.

\section{DISCUSSION}

Studies conducted by J. A. Castro-Rodriguez et al in Chile [3] showed that many respiratory viruses like Respiratory syncytial virus, Influenza virus, Para influenza virus and adenovirus have temporal association with meningococcal disease. The case discussed here also gives a clinical history similar to flu like symptoms following which he developed severe respiratory infection. Though the patient was not investigated for a viral etiology, he was given Oseltamivir phosphate tablet which could have added to the recovery of 
such an elderly patient. In all the studies quoted by J. A. Castro-Rodriguez et al and in their own studies, they have discussed that $10 \%$ of the population are carriers of Meningiococci, hence any viral infection causing abrasion to the respiratory tract will promote the entry of Meningiococci into the blood. A primary respiratory infection and sepsis due to meningiococci without meningitis is a rare clinical presentation.

Cases of Meningococcal pneumonia seen over 25 years (1974 to 1998) were studied by Winstead JM et al [4]. It was a remarkable study in which they traced only 58 cases from literature showing that this is a rare clinical presentation. The blood cultures were positive for $42(79.3 \%)$ cases. All these cases with bacteremia did not develop the syndrome of meningococcemia or its associated complications, similar to our case here. In their study $80 \%$ cases were treated with Penicillin and the rest with Cephalosporins.

The meningococcal isolate obtained in our case was resistant to Penicillin and third generation Cephalosporin, Ceftriaxone showing that ESBL producing meningococci has also emerged. This is indeed a new threat to the community because majority of cases of meningococcal infections are treated with Penicillin or third generation Cephalosporins. The isolate was also resistant to Ciprofloxacin which is the common chemo prophylactic drug given to prevent the spread of infection to all the contacts of the patient and laboratory workers dealing with the clinical samples of the patient.

\section{CONCLUSION}

The antibiotic resistance pattern of meningococci is changing with time. ESBL producing and Ciprofloxacin resistant strains are emerging, posing a threat for the treatment and chemoprophylaxis of Neisseria meningitidis.

\section{DECLARATION OF INTERESTS}

There are no conflicts of interest

\section{ACKNOWLEDGEMENT}

We sincerely thank the Public Health laboratory of Thiruvananthapuram for helping us to identify the isolate of our case. We also extend our gratitude to the National center for disease control, who helped us to confirm our findings.

\section{REFERENCES}

[1] Rosenstein NE, Perkins BA, Stephens DS, Popovic T, Hughes JM, Meningococcal disease. N Engl J Med 2001;344(18): 1378-88.

[2] Matthias Vossen, Dieter Mitteregger, Christoph SteiningerMeningococccal pneumonia, Vaccine (2016) 4364-4370.

[3] J.A. Castro-Rodriguez, L. Jakubson,O. Padilla, D. Gallegos, R. Fasce, P. Bertrand, I. Sanchez, and C. Perret, Many respiratory viruses have temporal association with meningococcal disease, Allergology and Immunopathology (Allergologia et Immunopathologia), 2015-09-01, Volume 43, Issue 5, pp. 487-492, Copyright (C) 2014 SEICAP.

[4] Winstead JM, McKinsey DS, Tasker S, De Groote MA, Baddour LM. Meningococcal pneumonia: characterization and review of cases seen over the past 25 years ,Clin Infect Dis. 2000 Jan;30(1):87-94. 